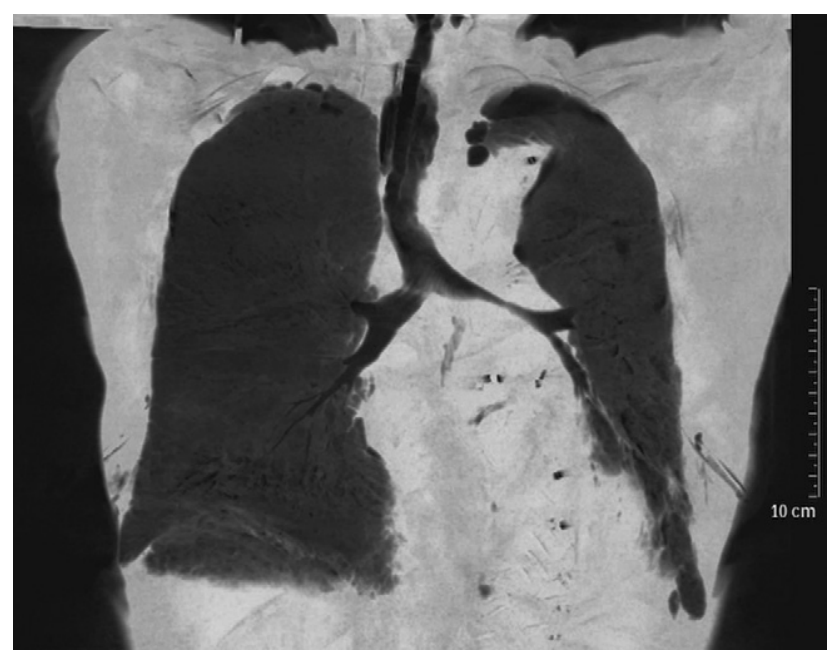

FIGURE 2. Minimum intensity projection showing compression of the left main bronchus. Minimum intensity projection demonstrates areas of lowest density, being equivalent to air. Other structures appear gray or black because of their density.

been described yet. Options could be open repair or dilatation with or without endobronchial stenting.

Madden, Loke, and Sheth ${ }^{5}$ reported a series of 31 patients undergoing bronchial stenting for airway compression. Clinical outcome was poor owing to obstructing granulation, mucus plugging, recurrent respiratory infections, and stent migration/fracture. Thus the value of stenting in airway compression is questionable and at best represents a palliative treatment. Another conceivable option for such patients is surgery. However, nothing has been reported so far, but a higher surgical risk can be anticipated owing to the potential for severe bleeding. In this case, to our understanding, the only reasonable access to the hematoma was the left-sided thoracotomy, which we were able to successfully perform.

\section{CONCLUSIONS}

Left-sided aortic aneurysmectomy is a reasonable option to treat bronchial compression after EVAR.

\section{References}

1. Parodi JC, Palmaz JC, Barone HD. Transfemoral intraluminal graft implantation for abdominal aortic aneurysms. Ann Vasc Surg. 1991;5:491-9.

2. Gopaldas RR, Huh J, Dao TK, LeMaire SA, Chu D, Bakaeen FG, et al. Superior nationwide outcomes of endovascular versus open repair for isolated descending thoracic aortic aneurysm in 11,669 patients. J Thorac Cardiovasc Surg. 2010; 140:1001-10.

3. Morales JP, Greenberg RK, Lu Q, Cury M, Hernandez AV, Mohabbat W, et al. Endoleaks following endovascular repair of thoracic aortic aneurysm: etiology and outcomes. J Endovasc Ther. 2008;15:631-8.

4. Morales JP, Chan YC, Bell RE, Reidy JF, Taylor PR. Endoluminal repair of distal aortic arch aneurysms causing aorto-vocal syndrome. Int J Clin Pract. 2008;62: 1511-4.

5. Madden BP, Loke TK, Sheth AC. Do expandable metallic airway stents have a role in the management of patients with benign tracheobronchial disease? Ann Thorac Surg. 2006;82:274-8.

\title{
Right ventricular exclusion for a neonatal patient with Ebstein anomaly: A free wall resection of the right ventricle
}

\author{
Takuya Kawabata, MD, PhD, Shingo Kasahara, MD, PhD, Sadahiko Arai, MD, PhD, and \\ Shunji Sano, MD, PhD, Okayama, Japan
}

The treatment of neonatal patients with severe Ebstein anomaly remains challenging for cardiac surgeons and pediatric cardiologists. The enlarged right side of the heart induces cardiopulmonary dysfunction. Since the first report

From the Department of Cardiovascular Surgery, Okayama University Graduate School of Medicine, Dentistry, and Pharmaceutical Sciences, Okayama, Japan. Disclosures: Authors have nothing to disclose with regard to commercial support. Received for publication Dec 7, 2010; revisions received May 2, 2011; accepted for publication May 23, 2011; available ahead of print July 1, 2011.

Address for reprints: Takuya Kawabata, MD, PhD, Department of Cardiovascular Surgery, Okayama University Graduate School of Medicine, Dentistry, and Pharmaceutical Sciences, 2-5-1 Shikata, Okayama, 700-8558, Japan (E-mail: ktakuya@pop01.odn.ne.jp).

J Thorac Cardiovasc Surg 2011;142:1582-4

$0022-5223 / \$ 36.00$

Copyright $(\odot 2011$ by The American Association for Thoracic Surgery doi:10.1016/j.jtcvs.2011.05.019 by Starnes, ${ }^{1}$ Reemtsen, ${ }^{2}$ and their coworkers, several evolutions of a single ventricular palliative operation have been reported. We herein describe a neonatal patient with Ebstein anomaly who underwent a free wall resection of the right ventricle $(\mathrm{RV})$ in combination with single ventricular palliative surgery.

\section{CLINICAL SUMMARY}

A male infant was born at 38 weeks' gestation by normal vaginal delivery with a birth weight of $2.55 \mathrm{~kg}$. Ebstein anomaly was diagnosed by fetal ultrasound cardiography (UCG). Postnatal UCG showed massive tricuspid regurgitation with plastering of the tricuspid septal and posterior leaflets, membranous pulmonary atresia, large atrial septal defect, compression of the left ventricle (LV) by the 


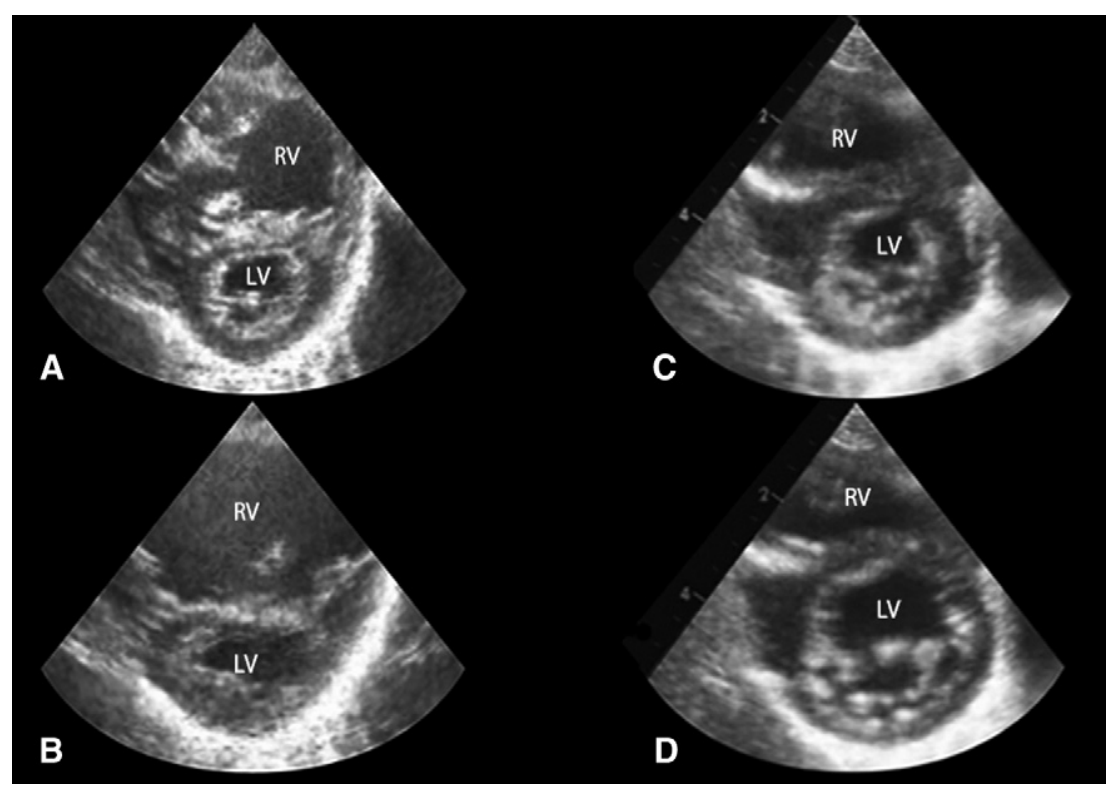

FIGURE 1. A and B, Preoperative echocardiogram in the end-systolic and end-diastolic phases, respectively (short-axis view). The IVS is shifted toward the LV side by the enlarged RV, especially in the end-diastolic phase. C and D, Postoperative echocardiograms in the end-systolic and end-diastolic phases, respectively (short-axis view). The IVS motion becomes normalized and the LV demonstrates a round shape, thus leading to an increase of the LV volume in the end-diastolic phase. IVS, Interventricular septum; $L V$, left ventricle; $R V$, right ventricle.

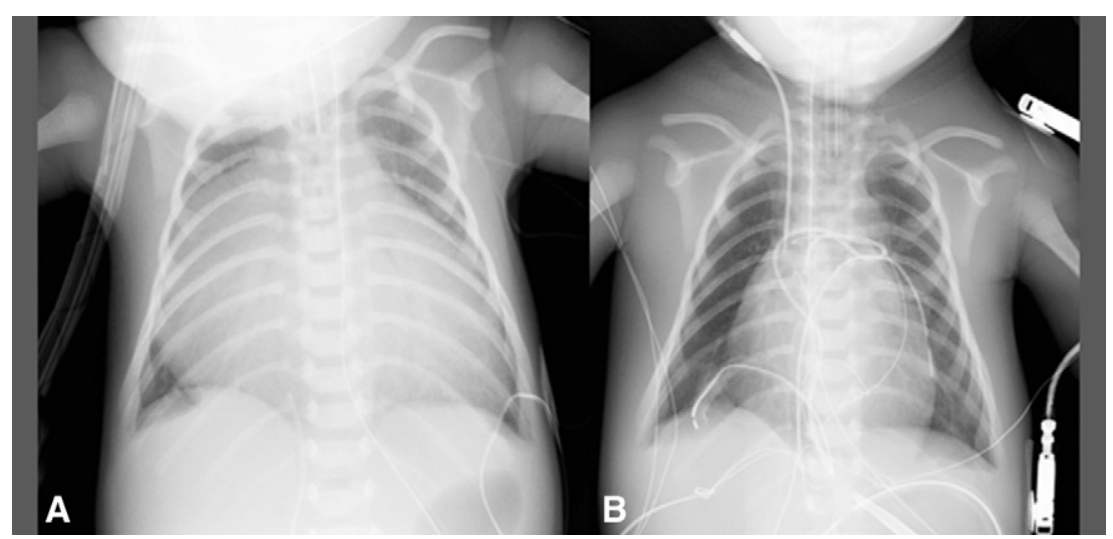

FIGURE 2. A and B, Preoperative and postoperative chest x-ray films, respectively. The cardiothoracic ratio decreased from 0.90 to 0.60 . The heart was smaller postoperatively, thus providing the lungs with more space to expand.

enlarged RV, especially in the diastolic phase, and paradoxic motion of the interventricular septum (IVS) (Figure $1, A$ and $B$ ). The estimated peak RV pressure by tricuspid regurgitation jet was $15 \mathrm{~mm} \mathrm{Hg}$ and the RV was 1.5 $\mathrm{mm}$ in thickness. The Great Ormond Street ratio ${ }^{3}$ was 1.6. The cardiothoracic ratio by chest radiography was 0.90 (Figure 2, A). He was intubated and lipoprostaglandin $\mathrm{E}_{1}$ was administered immediately after birth. Pulmonary resistance decreased day by day, and congestive heart failure progressed. Inotropic support and nitrogen inhalation were started on the second and sixth day, respectively. During this period, the repeated UCG did not detect any pulmonary forward flow.
On the seventh day, he underwent a free wall resection of the RV in combination with single ventricular palliative surgery: closure of the tricuspid valve with fenestration, a resection of the RV free wall, and creation of a systemicpulmonary shunt. Through a median full sternotomy, cardiopulmonary bypass with aortic and bicaval cannulations was established. After cardioplegic cardiac arrest, an oblique right atriotomy was made and the pulmonary atresia was confirmed by direct viewing. Then, the orifice of the tricuspid valve was closed by its leaflets between the anterior and septal leaflets and by an expanded polytetrafluoroethylene patch with a 3.5-mm fenestration between the anterior and posterior leaflets. After release of the aortic crossclamp, 
in addition to a free wall resection of the right atrium, the anterior free wall of the thin redundant $\mathrm{RV}$ was also resected elliptically and closed directly. The RV wall was thin muscular tissue without fibrosis. The resected area was determined by the RV branch of the right coronary artery and IVS. The procedures were performed with a beating heart to prevent overresection. A systemic-pulmonary shunt was created between the right brachiocephalic artery and the right pulmonary artery with a $3.5-\mathrm{mm}$ expanded polytetrafluoroethylene graft.

On the third postoperative day, delayed sternal closure was carried out. During the operation, additional plications of the RV free wall were performed. After the operation, the cardiothoracic ratio was decreased to 0.60 (Figure 2, B), and estimated lung compliance was increased from 2.04 to $2.64 \mathrm{~mL} /$ $\mathrm{cmH}_{2} \mathrm{O}$ on ventilatory support. Postoperative UCG showed improvement of IVS motion and the LV function (Figure 1, $C$ and $D$ ): the eccentricity index was decreased from 1.85 to 1.16 , the end-diastolic volume was increased from 2.4 to 7.0 $\mathrm{mL}$, and the ejection fraction of the $\mathrm{LV}$ was increased from 0.45 to $0.78 .{ }^{4}$ His postoperative course was uneventful. He has been followed up for 6 months and is currently waiting for a bidirectional cavopulmonary shunt operation.

\section{DISCUSSION}

Ebstein anomaly is a rare congenital heart defect of the tricuspid valve and RV; however, several reports have also shown abnormalities of the LV. ${ }^{2,4}$ These abnormalities include abnormal motion of the IVS and compression of the LV, which are induced by the enlarged right heart. The enlarged heart also occupies so much space in the thoracic cavity that the lungs are rendered hypoplastic.

Since 1996, to reduce the deleterious effects of the enlarged RV, we have performed free wall resection of the RV for pediatric patients with Ebstein anomaly in combination with one and a half ventricle repair or total cavopulmonary connection. ${ }^{5}$ In these patients, the small right heart helps the IVS motion and the LV function to improve and also provides the lungs with more space to expand immediately after the operation. These experiences have therefore led us to indicate this procedure for the neonatal patient.

This is the first published report, to our knowledge, of a neonatal patient with Ebstein anomaly who underwent a free wall resection of the RV in combination with single ventricular palliative surgery.

\section{References}

1. Starnes VA, Pitlick PT, Bernstein D, Griffin ML, Choy M, Shumway NE. Ebstein's anomaly appearing in the neonate: a new surgical approach. J Thorac Cardiovasc Surg. 1991;101:1082-7.

2. Reemtsen BL, Fagan BT, Wells WJ, Starnes VA. Current surgical therapy for Ebstein anomaly in neonates. J Thorac Cardiovasc Surg. 2006;132:1285-90.

3. Shinkawa T, Polimenakos AC, Gomez-Fifer CA, Charpie JR, Hirsch JC, Devaney EJ, et al. Management and long-term outcome of neonatal Ebstein anomaly. J Thorac Cardiovasc Surg. 2010;139:354-8.

4. Takagaki M, Ishino K, Kawada M, Ohtsuki S-i, Hirota M, Tanabe Y, et al. Total right ventricular exclusion improves left ventricular function in patients with end-stage congestive right ventricular failure. Circulation. 2003;108(suppl II): II226-9.

5. Sano S, Ishino K, Kawada M, Kasahara S, Kohmoto T, Takeuchi M, et al. Total right ventricular exclusion procedure: an operation for isolated congestive right ventricular failure. J Thorac Cardiovasc Surg. 2002;123:640-7. 